\title{
Association between Serum Ceruloplasmin level and Dyslipidemia: Study in Tertiary care Teaching Hospital
}

\author{
Dhat $\mathbf{V}^{1}$, Tinaikar $\mathbf{M}^{2}$, Sontakke $\mathbf{A}^{3}$ \\ ${ }^{1}$ Dr Vaishali Dhat, M D, Associate Professor, Department of Biochemistry, ${ }^{2}$ Miss Madhura Tinaikar \\ Intern, ${ }^{3}$ Dr Alka Sontakke, Professor \& Head, Department of Biochemistry. All from MIMER Medical College, Talegaon \\ Dabhade
}

Address for correspondence: Dr Vaishali Dhat, Email: vaishdhat@yahoo.com

\begin{abstract}
Introduction: Dyslipidemia is one of the major morbid events preceding CAD all around. The conventional risk factors have failed to predict the risk of coronary events in around $30-40 \%$ cases; hence an emphasis is being given to search new able risk factors. With this respect the study tried to evaluate the correlation of serum ceruloplasmin levels in dyslipidemic patients. The aim of the study was to study the correlation of serum ceruloplasmin and Dyslipidemia. Methods: 60 Subjects were screened for dyslipidemia by estimation of serum total cholesterol, triacylglycerol, HDL and LDL and were categorized into cases and controls and serum ceruloplasmin was estimated in all of them. Results: Serum mean ceruloplasmin level in dyslipidemics was significantly raised as compared to controls. Odds ratio as high as 15.54 shows a positive correlation of serum ceruloplasmin and dyslipidemia. Ceruloplasmin levels are associated with dyslipidemia ( especially LDL values) showing 'positive r values' and 'p' value is significant. Discussion: Raised serum ceruloplasmin levels in dyslipidemics as compared to normal healthy subjects suggest that dyslipidemics are more prone for rise in ceruloplasmin levels than the healthy subjects supporting our hypothesis that raised serum ceruloplasmin levels could enhance the risk for coronary artery diseases. Raised serum Ceruloplasmin level in association with LDL values in dyslipidemics should be considered as an added risk factor for CAD. Antioxidant supplementation orally to reduce ceruloplasmin levels can be considered as a new approach of treatment in the future.
\end{abstract}

Key words: Ceruloplasmin, Coronary artery disease, Dyslipidemia, prooxidant,

\section{Introduction}

With the explosive rise in the incidence of coronary artery disease $(\mathrm{CAD})$ it is projected to be the leading cause of morbidity and mortality among Indians by the year $2015^{1}$. The World Health Organization (WHO) predicts that deaths due to circulatory system diseases are projected to

Manuscript received: $10^{\text {th }}$ July 2013

Reviewed: $13^{\text {th }}$ July 2013

Author Corrected: $20^{\text {th }}$ July 2013

Accepted for Publication: $30^{\text {th }}$ July 2013 double between 1985 and $2015^{2}$. The presently available risk factors to predict the risk of morbid coronary events fail to do so in about $30 \%$ to $40 \%$ of the cases, so a search must be done for new risk factors that can add to the current list and will help for further evaluation. Ceruloplasmin ${ }^{1}$ is and $\alpha-2$ globulin that carries most of the copper in the blood. Although its elevation after inflammation and trauma has led to its classification as an acute phase 
reactant, its physiological role is still uncertain and has been a subject to various speculations, investigations and contradictions. Multiple biochemical activities of ceruloplasmin have been described including oxidation of various amines, oxidation of $\mathrm{Fe}^{++}$to $\mathrm{Fe}^{+++}$for its subsequent uptake by transferrin and antioxidant activity against lipid peroxidation.

In contrast to this; ceruloplasmin is also considered as a pro-oxidant which may be central in its primary function that is as a participant in the host defence system through an injurious oxidant action on host biomolecules. The oxidant activity of ceruloplasmin may be a causative factor for atherosclerosis ${ }^{3}$

Dyslipidemia is elevation of plasma cholesterol and or triacylglycerol or a low high-density lipoprotein or decreased serum high density lipoprotein level that contributes to the development of atherosclerosis. It is a primary major risk factor for coronary artery disease (CAD) and may even be a pre-requisite for coronary artery disease occurring before other major risk factors come into play.

The role of monocytes and macrophages needs to be carefully scrutinized with respect to lipid peroxidation in vivo. Oxidation of lipids \& lipoproteins by macrophages is an important event during atherogenesis. Activation of monocytic cells by 'zymosan' and other agonists result in release of multiple oxidant species and consequent oxidation of LDL (Low Density Lipoprotein).

The studies ${ }^{4}$ now show that ceruloplasmin is secreted by zymosan-activated U-937 monocytic cells and that the protein has an important role in lipid oxidation by these cells. Exogenous addition of purified hormone ceruloplasmin stimulates U-937 cell oxidation of LDL to same extent as that of zymosan. In contrast to previous cell free experiments, ceruloplasmin by itself only

oxidizes LDL in the presence of cells the mechanism of which the cells overcome the inhibition by medium components has not been ascertained. Activated monocytes and macrophages are recognized for their remarkable diversity of secreted products including multiple reactive oxygen and nitrogen species involved in defence mechanisms. The same oxidation reactions may also cause secondary oxidative damage to host macromolecules and tissues during chronic inflammatory processes.

There is now abundant evidence that particles resembling oxidatively modified LDL are present in atherosclerotic lesions. The monocytic cells achieve optimal oxidation rates by utilizing their own transition metal ions. Macrophage derived hypochlorous acid or nitric oxide may be precursors of highly reactive hydroxyl radicals by metal ion independent mechanisms.

Studies done recently show that physiological concentrations of purified human ceruloplasmin (200$400 \mu \mathrm{gm} / \mathrm{ml}$ ) in healthy adults increase the oxidation of LDL in vitro by up to 50 folds when measured as TBARS ( Thiobarbituric acid reactive substances) ${ }^{4}$.

Hence, the study was designed to study the status of serum ceruloplasmin in dyslipidemia

\section{Material and Methods}

The study was carried out at Bhausaheb Sardesai Rural Hospital Talegaon (D). The subjects for the study were selected with written informed consent. Assuming the prevalence of dyslipidemia in all lipid profile samples to be $50 \%$ and with an allowable error of $\pm 10 / 20 \%$ and confidence interval of $95 \%$ the estimated sample size is 60 samples. Out of which approximately $50 \%$ would be dyslipidemic. These subjects were categorized under following groups:-

Control group: 30 age and sex matched healthy individuals with normal lipid profile.

Test group: 30 Individuals with abnormal lipid profile without any associated diseases like DM, HTN etc.

The procedure for serum ceruloplasmin estimation is as follows

Available online at: $\underline{\text { www.ijmrr.in }} \quad 85$ | P a g e 
(Method of Somani - Ambade Govt of India Patent No:

$19235619)^{5}$ Serum Ceruloplasmin level was estimated by above method on semi automated analyser ERBA CHEM $5 \mathrm{X}$ at $400 \mathrm{~nm} \lambda)$

Kinetic method amenable to automation for ceruloplasmin estimation with inexpension

$50 \mu$ sample $+1 \mathrm{ml}$ reagent $(1) \rightarrow$ kept at room temperature for $1 \mathrm{~min} \rightarrow 150 \mu \mathrm{l}$ reagent $(2) \rightarrow$ measure in kinetic mode with factor 2012, lag time 10 secs.

Lipid profile was assessed by standard methods:

Cholesterol: Cholesterol oxidase ${ }^{6}$ method

Serum Triacylglycerol: Trinder's ${ }^{7}$ method

Serum LDL: Direct LDL $\mathrm{kit}^{8}$ method

Serum HDL: Direct HDL $\mathrm{kit}^{8}$ method

Criteria for Dyslipidemia: According to adult treatment panel III guidelines

Serum Total Cholesterol: $>200 \mathrm{mg} / \mathrm{dl}$
Serum Low Density Lipoprotein: $>100 \mathrm{mg} / \mathrm{dl}$

Serum High Density Lipoprotein: $<40 \mathrm{mg} / \mathrm{dl}$

Serum Triacylglycerol: $>150 \mathrm{mg} / \mathrm{dl}$

With presence of one or more of the above parameters, the individual is considered as dyslipidemic.

Inclusion criteria: Dyslipidemia

Exclusion criteria: Associated major illness like Hypothyroidism, HTN, DM etc that can independently increase the risk of CAD.

Statistical Analysis: The data was analyzed by using SSPS version 14.0 .

Values were expressed as mean +/- SD. Mann Whitney test for significance was used Correlation was calculated using Pearson's correlation

\section{Results}

Table 1: Comparison of lipid profile in Group I and Group II

\begin{tabular}{|c|c|c|c|c|c|}
\hline & Total Cholesterol & LDL & TG & HDL & Ceruloplasmin \\
\hline Group II & $162.06+/-43.07$ & $128.6+/-33.68$ & $207.93+/-114$ & $38.3+/-7.72$ & 824.2 \\
\hline Group I & $119.77+/-28.09$ & $88.06+/-12.22$ & $106.6+/-17.57$ & $387+/-0.76$ & 421 \\
(controls) & & & & & 4.441 \\
\hline $\mathbf{Z}$ & 3.951 & 4.945 & 6.069 & 0.112 & 0.0001 \\
\hline P & 0.0001 & 0.001 & 0.0001 & 0.911 & \\
\hline
\end{tabular}

$\mathrm{Z}=$ value of significance according to Mann Whitney test $\mathrm{P}=\mathrm{P}$ value

Means (table 1 and Graphs 1a to 4b) are statistically significant for dyslipidemics and controls for all values except HDL with test values being significantly higher. The test applied was Mann Whitney test for significance.

- There was a statistically significant rise in TC, LDL and TG levels in dyslipidemics when compared with controls whereas serum HDL levels did not show any significant change.

- Serum Ceruloplasmin levels were significantly raised in dyslipidemics when compared with control group 
Table 2: Correlation of Serum Ceruloplasmin and Lipid profile in cases and controls

\begin{tabular}{|c|c|c|c|c|}
\hline & \multicolumn{2}{|c|}{ Control } & \multicolumn{2}{c|}{ Test } \\
\hline Total Cholesterol & 0.116 & 0.507 & 0.139 & 0.465 \\
\hline LDL & 0.113 & 0.519 & 0.433 & 0.017 \\
\hline TG & 0.114 & 0.055 & 0.114 & 0.448 \\
\hline HDL & 0.112 & 0.522 & 0.113 & 0.553 \\
\hline
\end{tabular}

Significant positive correlation of serum ceruloplasmin was seen only with LDL in Dyslipidemics when compared with other parameters of lipid profile (TC, TG, HDL) in group I and group II (table1) controls showed no such correlation.

Correlations (table 2) were calculated using Pearsons correlation coefficient. However when correlations were seen separately for tests and controls, ceruloplasmin was positively correlated with LDL in dyslipidemics and with no other parameter of lipid profile $(r=0.433, p<0.05)$ but not in control. Ceruloplasmin was negatively associated with TG in controls, but the correlation is not statistically significant

Table 3: Odds ratio

\begin{tabular}{|c|c|c|}
\hline & $\begin{array}{c}\text { Serum Ceruloplasmin } \\
\text { ( less than 520 IU/Lit ) }\end{array}$ & $\begin{array}{c}\text { Serum Ceruloplasmin } \\
\text { ( more than 520 IU/Lit ) }\end{array}$ \\
\hline Control Group & 27 subjects & 3 subjects \\
\hline Dyslipidemic Cases & 11 subjects & 19 subjects \\
\hline
\end{tabular}

The normal serum ceruloplasmin level is $325-520 \mathrm{IU} / \mathrm{Lit}$ Thus the Odds ratio as high as 15.54 shows a positive correlation of serum ceruloplasmin and dyslipidemia supporting our hypothesis pointing that, raised ceruloplasmin levels in dyslipidemic patients can form an added risk factor for coronary heart disease.

Association of LDL is more consistent with raised ceruloplasmin values than any other dyslipidemic parameter. Also the percentage of the control group showing raised ceruloplasmin levels is as low as $10 \%$.

\section{Comparison of lipid profile and ceruloplasmin levels of cases and controls}

Lipid profile results in 60 subjects. 
(Graph 1 a)

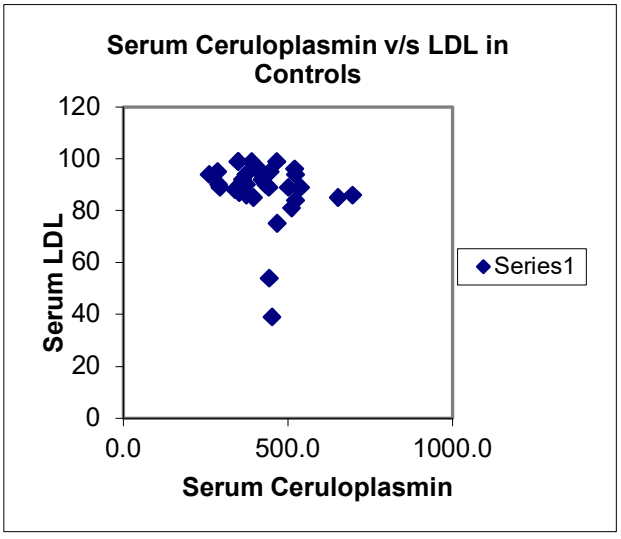

(Graph 2 a)

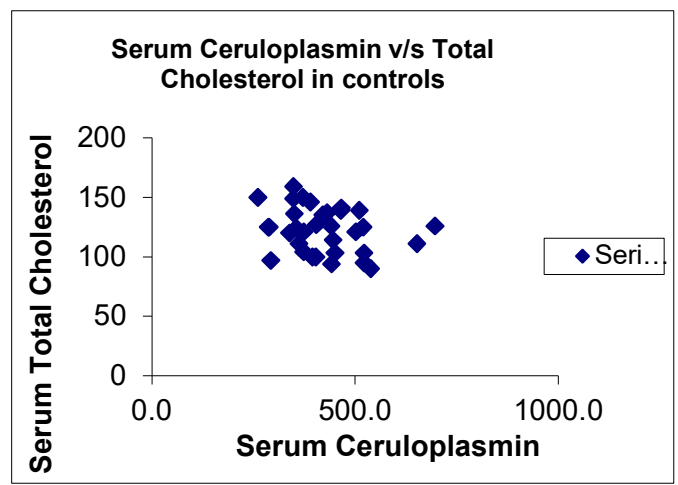

(Graph 3 a)

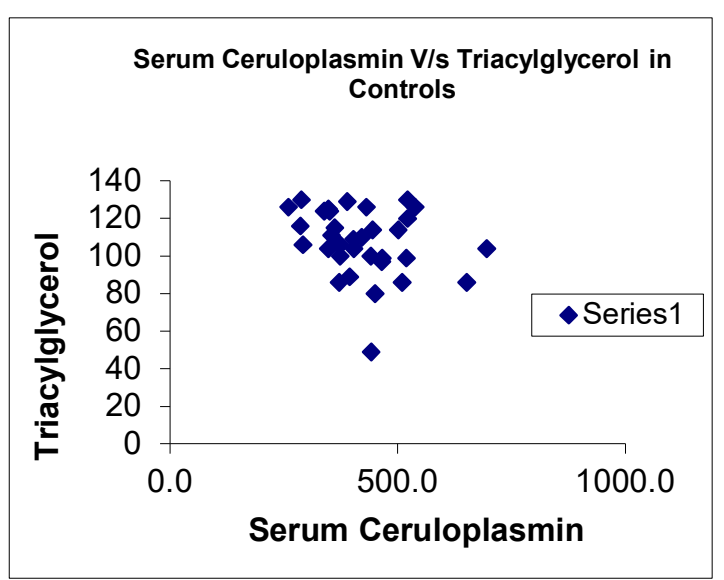

(Graph 1 b)

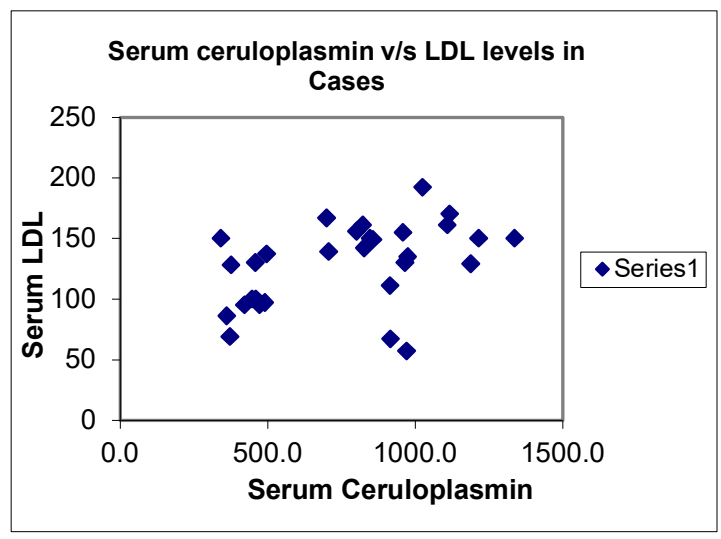

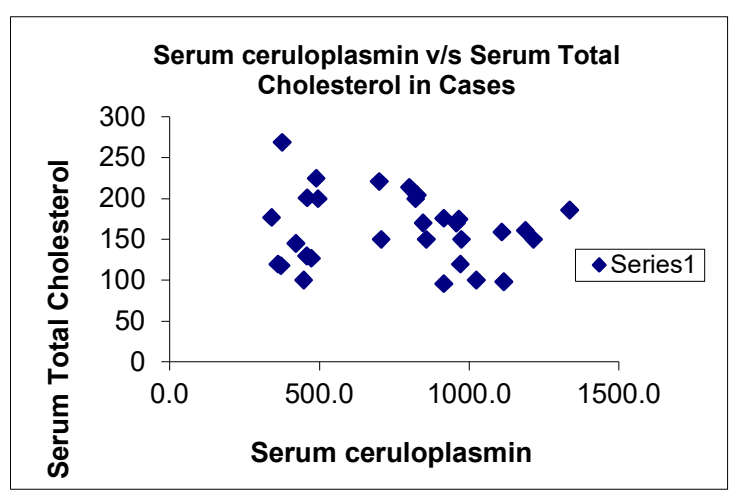

(Graph 3 b)

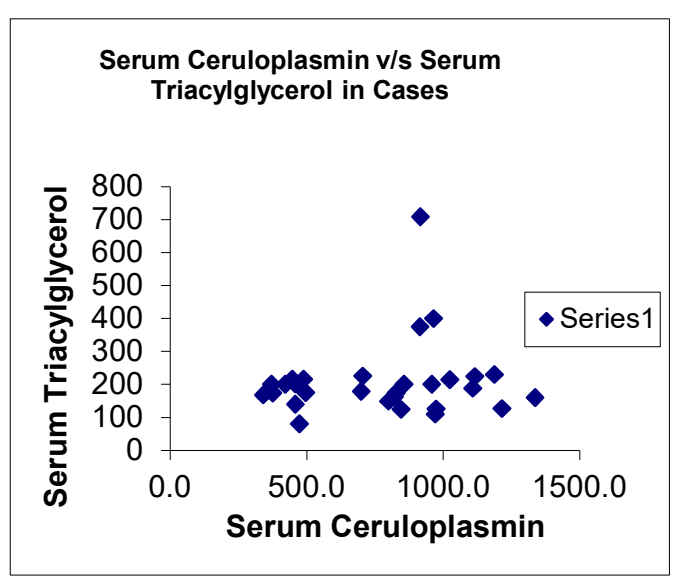


(Graph 4 a)

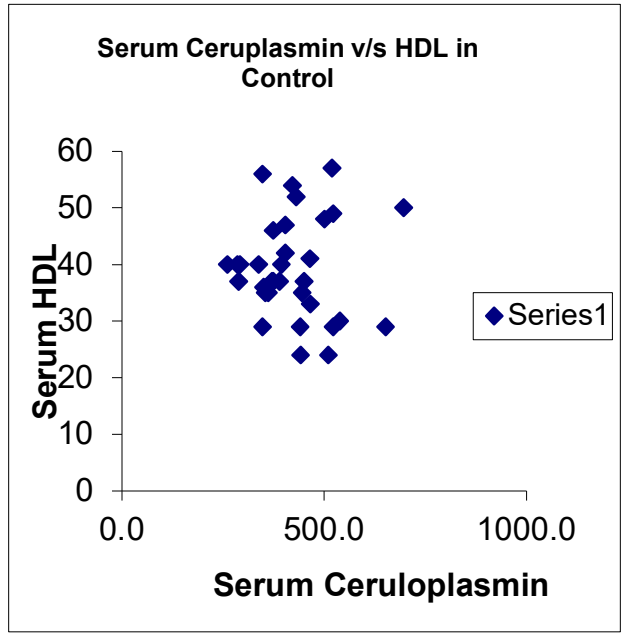

(Graph 4 b)

Serum Ceruloplasmin v/s Serum HDL levels in Cases

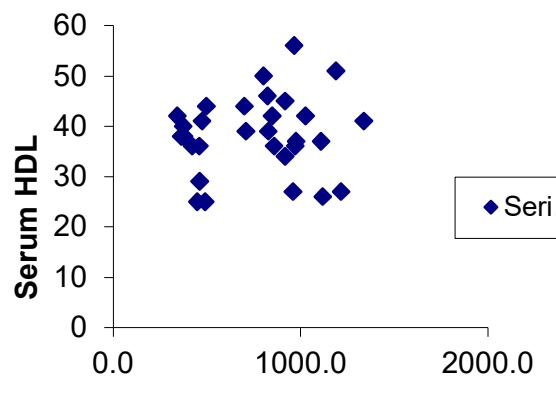

Serum Ceruloplasmin

\section{Discussion}

Dyslipidemia is one of the most strongly predictive cardiovascular risk factor for $\mathrm{CAD}^{9}$. Atherosclerosis represents the pathological process that typically underlies cardiovascular morbidity and mortality, formation of plaques in the intima and media of the arterial wall ${ }^{3}$. Atherosclerotic plaque results from the progressive accumulation of cholesterol, diverse lipids in native and oxidized forms, extracellular matrix materials and inflammatory cells ${ }^{10}$.

Atherogenic dyslipidemia; a highly prominent cardiovascular risk factor is intimately associated with premature atherosclerosis and correspond to an imbalance between excess circulating levels of apoB containing lipoproteins (LDL, TG) compared with levels of antiatherogenic apoA1 containing lipoproteins (HDL) ${ }^{11}$. In our study dyslipidemics had raised levels of LDL, TC, TG whereas HDL was in the normal range in both the groups. There was statistically significant rise in serum total cholesterol, TG and LDL levels when dyslipidemics were compared with the normal group (Table no 1).

LDL is the major vehicle for transport of cholesterol not only to the peripheral tissues but also to the arterial wall ${ }^{12}$ and ionic interaction of positively charged domains of apoB and negatively charged proteins of extracellular

International Journal of Medical Research and Review matrix including proteoglycans, collagen and fibronectin leads to intimal retention of apoB containing lipoproteins a major initiating factor in atherogenesis ${ }^{13}$. Ceruloplasmin has varied biochemical roles in the body like ferroxidase activity and as a marker of inflammation as acute phase reactant. There was a significant rise observed in the dyslipidemics $(\mathrm{p}<0.001)$ than the normal subjects in the study. An increase in ceruloplasmin levels in dyslipidemics may be due to its synthesis by the activated macrophages.

These findings are similar to Virgolici et al. an increase in serum ceruloplasmin levels could generate an excess of oxidized LDL which causes atherosclerosis ${ }^{14}$ In this study when the ceruloplasmin levels were compared between dyslipidemics and normal healthy subjects the odds ratio was 15.54 which means the dyslipidemics are more prone for rise in ceruloplasmin levels than the healthy subjects supporting our hypothesis that raised serum ceruloplasmin levels could enhance the risk for coronary artery diseases.

When the levels of ceruloplasmin were correlated with the levels of TC, TG, LDL and HDL; in dyslipidemics we found a statistically significant strong positive correlation between ceruloplasmin and LDL levels. It was seen only with the LDL levels. This may have a bearing on the fact ceruloplasmin being a pro-oxidant may increase the levels

Available online at: www.ijmrr.in 89 | P a g e 
of oxidized LDL ${ }^{15}$. Thus raised serum ceruloplasmin may further enhance the risk of CAD in patients with raised LDL levels. Further studies are required to find out whether there is any cause and effect relationship between LDL and serum ceruloplasmin levels.

\section{Conclusion}

The present study showed that serum ceruloplasmin levels of dyslipidemics are significantly higher than normal healthy subjects. Thus raised ceruloplasmin can be considered as an added risk factor in dyslipidemic patients with regard to coronary artery disease.

LDL values in dyslipidemic patients require special attention because of the great significance associated with the raised ceruloplasmin levels, and if found raised then addition of antioxidants to the conventional ways of treatment may prove therapeutically useful.

Thus, Serum Ceruloplasmin level in association with LDL values in dyslipidemics should be considered as an added risk factor with a special role of antioxidants in the conventional therapy. Further follow up of such cases can thus be done as a future part of the study.

\section{Acknowledgement}

The authors are thankful to ICMR STS for the financial assistance to carry out this study. The authors are also thankful to Mrs Swati Raje, Statistician for the statistical analysis of this project.

\section{Conflict of interest: Nil}

Permission from IRB: Yes

\section{References}

1. A. Kumar, S. Nagtilak, R. Sivakanesan: Analysis of cardiovascular risk factors in normolipidemic acute myocardial infarct patients on admission based on aging A case controlled study from South Asia. The Internet Journal of Alternative Medicine. 2009 ; 8 (1)
2. Kontush A, Chantepie S, Chapman MJ. 2003. Small, dense HDL particles exert potent protection of atherogenic LDL against oxidative stress. Arterioscler. Thromb. Vasc. Biol.2003; 23: 1881-1888

3. Isselbacher, Braunwald, Wilson, Martin, Fauci, Kasper. Harrison's Principles of Internal Medicine 17th edition vol 2,Mcgraw Hill, 2006:1425-30

4. Virgolici B., Mohora M., Radoi V., Lixandru D., Stoian I., Gaman L., Coman A., Greabu M., Manuel-y-Keenoy B. Correlations between dysglycemia, markers of oxidative stress and inflammation in diabetic foot patients, Farmacia, 2011, 59 (2), 216-226

5. Somani BL, Ambade V. A kinetic method amenable to automation for ceruloplasmin estimation with inexpensive and stable reagents. Clin Biochem. 2007;40:571-4.

6. Myers G. L.,Kimberly M. et al, A reference method laboratory network for cholesterol : a model for standerdisation and improvement of clinical laboratory measurement ., clin . chem., 2000, 46, p (1762 1772).

7. Henry J.B., Clinical diagnosis and management of laboratory methods, 18th edition, W.B. Saunders Philadelphia, p (204-211).

8. Miller WG, Myers GL, Sakurabayashi I, Bachmann LM, Laudill SP, Dzerekonski A, Edwards S, Kimberly MM, Korzun WJ, Leary ET, Nakajima K, Nakamura M, Nilson G, Shamburek RD, Vetrovec GW, Warwick GR, Remaley AT, Seven Direct Methods for Measuring HDL and LDL Cholesterol Compared with Ultracentrifugation Reference Measurement Procedures Clinical Chemistry. June 2010; 56( 6): 977-986

9. Jellinger $\mathrm{P}$, The American Association of Clinical Endocrinologists Medical Guidelines for Clinical Practice for the Diagnosis and Treatment of Dyslipidemia and Prevention of Atherogenesis 2002 Amended Version. Endocr Pract. 2000;6(No.2)164-174

Available online at: $\underline{\text { www.ijmrr.in }} 90$ | P a g e 
10. Tenenbaum A, Fisman EZ, Motro M, Adler Y. Atherogenic dyslipidemia in metabolic syndrome and type 2 diabetes: therapeutic options beyond statins. Cardiovascu Diabetol 2006, 5:20.

11. Genest J, Frohlich J, Fodor G, Mcpherson R, Recommendation for the management of dyslipedemia \& the prevention of cardiovascular disease. CMAJ 2003;168(9):921-4

12. Yusuf S, Hawken S, Ounpuu S, Dans T, Avezum A, Lanas F, McQueen M, Budaj A, Pais P, Varigos J, Lisheng L Effect of potentially modifiable risk factors associated with Myocardial Infarction in 52 countries: case control study. Lancet. 2004 Sep 11-17;364(9438):937-52
13. Lusis AJ: Atherosclerosis. Nature 2000 sep 14; 407(6801): 233-241

14. Bogdana Vîrgolici, Maria Mohora, Laura Găman, Daniela Lixandru B. Manolescu, Anca Coman, Irina Stoian. Relation Between Inflammation And Oxidative Stress Markers In Diabetic Foot Patients. Romanian J. Biophys. 2008, 18(4) 273-282

15. Ehrenwald E, Chisolm GM, Fox PL. Intact human serum ceruloplasmin oxidatively modifies Low density lipoproteins. J Clin Invest. 1994 April; 93(4): 1493-1501.

\section{How to cite this article?}

Dhat V, Tinaikar M, Sontakke A. Association between Serum Ceruloplasmin level and Dyslipidemia: Study in Tertiary care Teaching Hospital. Int J Med Res Rev 2013;1(3):84-91. doi: 10.17511/ijmrr.2013.i03.03 